\title{
THE IMPACT OF MACROECONOMIC VARIABLES ON THE BUCHAREST STOCK EXCHANGE
}

\author{
Lecturer Phd Flavia Barna, flavia.barna@fse.uvt.ro \\ Associate Professor Phd Bogdan Dima,bogdan.dima@fse.uvt.ro \\ Associate Professor Phd, Marilen Pirtea, marilen.pirtea@fse.uvt.ro \\ West University of Timişoara, Romania
}

\begin{abstract}
The evolution of the Bucharest Stock Exchange is influenced by a number of factors that have a more or less significant impact upon the trend this market follows. The implementing of stimulating policies in what concerns the development of the financial market, strictly connected to the development of the national economy, implies both the awareness of these factors existence as well as the need of evaluating the impact they have.

The purpose of the present paper is to identify and quantify the impact of the macroeconomic variables, such as the inflation rate, interest rate or exchange rate upon the evolution of the Bucharest Stock Exchange.
\end{abstract}

\section{Introduction}

The Romanian capital market benefited from harmonized regulations to best standards and practices that stimulated its growth. Nevertheless, it was the same convergence process that amplified a number of vulnerabilities related to higher sensitivity to external shocks and a slowdown in growth in comparable terms.

For example, The Bucharest Stock Exchange index (BET) increased by 22.23 percent in 2006, while market liquidity - measured as turnover velocity (yearly turnover/market capitalization) - slightly decreased compared to the previous year to 13 percent. According to the Federation of European Stock Exchanges (FESE) Romania ranked tenth out of the 22 countries represented in terms of index growth, after Spain, Norway, Sweden, Austria, but ahead of Hungary or the Czech Republic.

The weaker performance of the stock exchanges in the CEECs was due to the global correction that took place between April-June 2006 (Chart 1), generated by the increasing uncertainties linked to interest rate in the US, the rise in inflationary pressures, depreciation of the US dollar, the price hikes on commodity markets and fears that the positive results at corporate level would not be sustainable. 
Yearly turnover and market capitalization

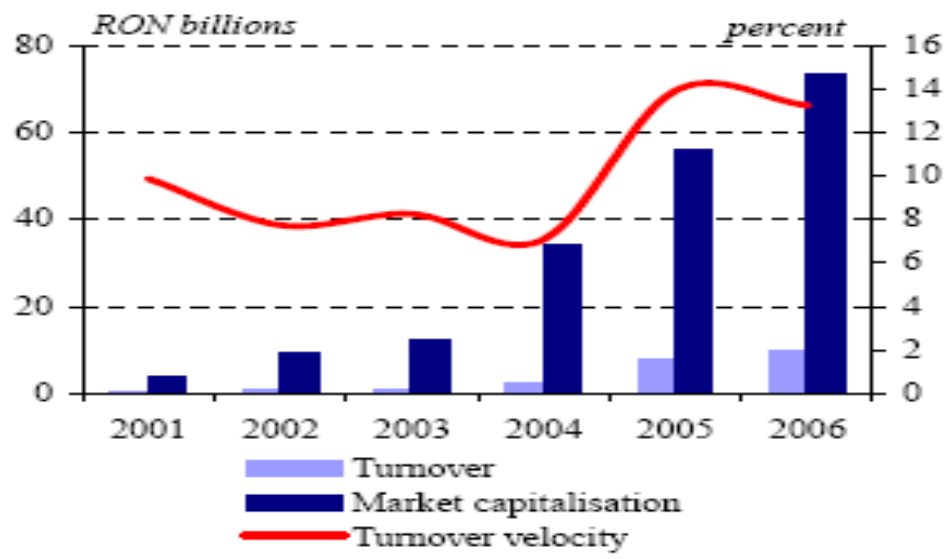

Source: www.bvb.ro

Evolution of average yearly $\mathrm{P} / \mathrm{E}$ ratios 2000-2006

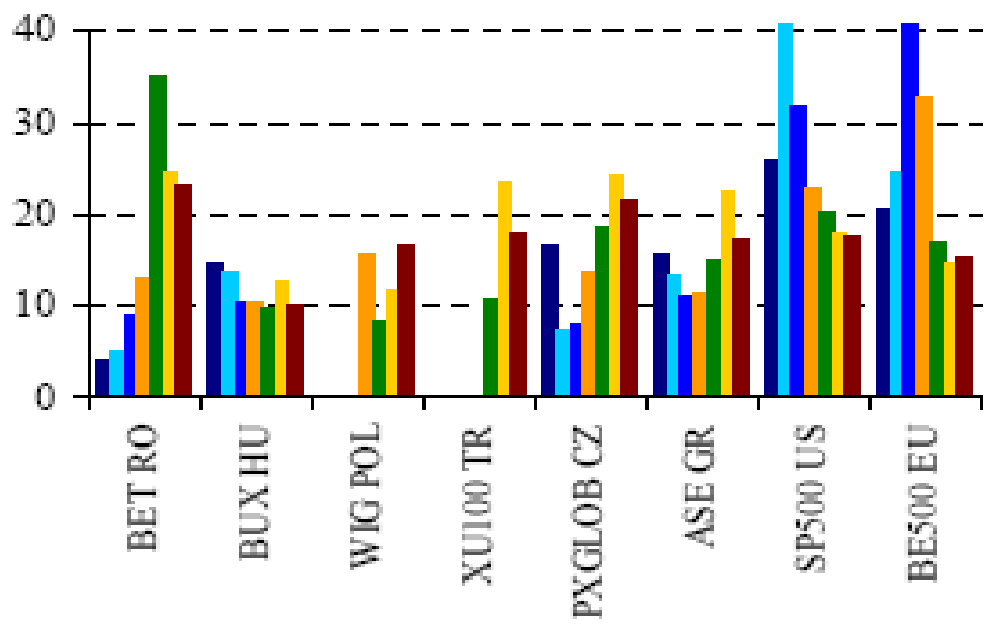

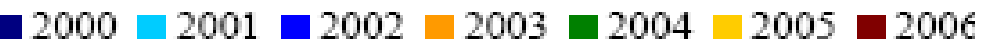

Source: www.bvb.ro

Chart 2 suggests a similar behavior of investors towards this region by showing a linear relationship between the liquidity level on those markets and the magnitude of corrections. The explanation could be: (1) initial shocks generated by capital outflows, which were proportional to the size of the markets or the presence of foreign investors, followed by local reactions amplified by the liquidity levels probably stemming from the presence of leverage on each of these markets, which was boosted by leverage; and (2) the pure contagion effect among regional markets. It could be asserted that economic factors may have fuelled the reactions in the case of Hungary and Turkey, but these markets are at the same time among the most liquid ones, and the role of fundamentals is inconclusive. The same Chart shows the advantage of the developed markets where in spite of the relatively high level of liquidity the corrections were significantly smaller. 
Developments in market indices

Chart 3.

(reference date: January 2005)

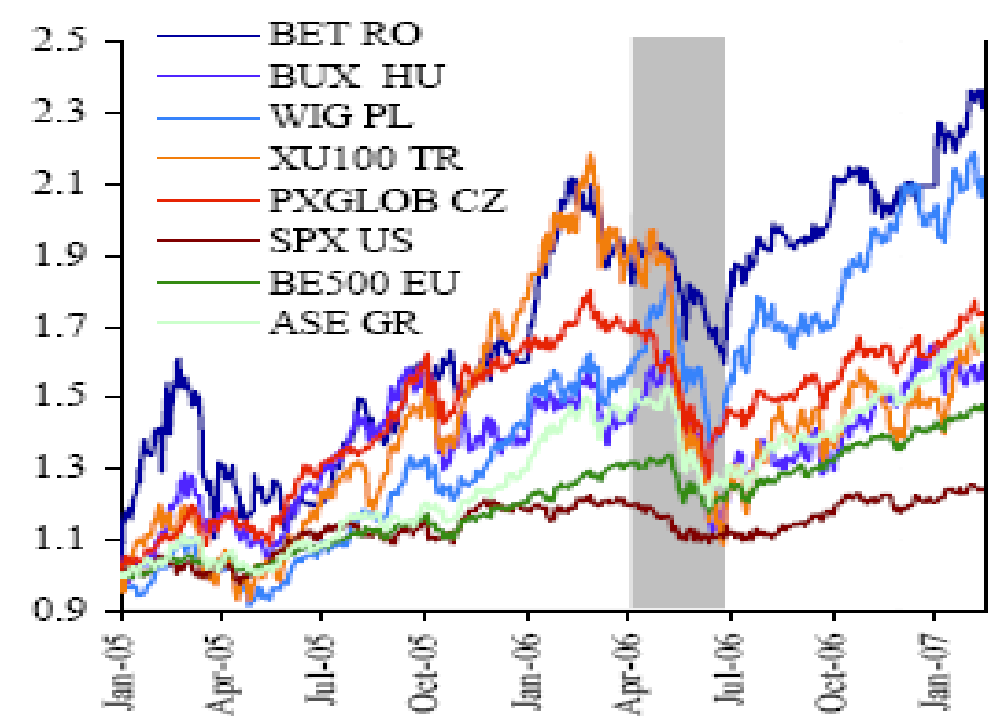

Source: Bloomberg, BSE, World Federation of Exchanges, FESE

Correction levels in relation to market liquidity

Chart 4.

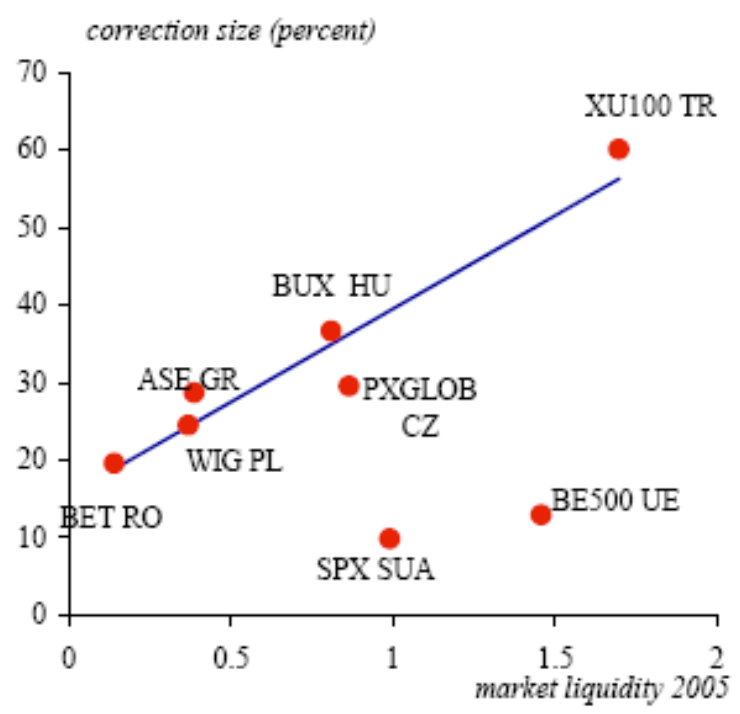

Source: Bloomberg, BSE, World Federation of Exchanges, FESE

The central element of the present paper consists of identifying and quantifying the impact that the macroeconomic variables, such as the inflation rate, the interest rate and the exchange rate upon the evolution of the composite index of the Stock Exchange of Bucharest.

Therefore, the paper offers a VEC model and presents its methodology in the second part of the paper. The third part is dedicated to implementing the model and obtaining the results and the last part contains the conclusions that were obtained after analyzing the obtained results. 


\section{The methodology}

In order to test the links between the performances of the investments funds and some macro-variables, a Vector Error Correction (VEC) could be involved. The VEC methodology presents several advantages. In particular, it allows building a model of the connections between some co-integrated variables, being extremely useful in the study of the economic fluctuations.

A VEC model is a particular restricted Vector Error (VAR) model designed for use with nonstationary series that are known to be co-integrated. The VEC has co-integration relations built into the specification so that it restricts the long-run behavior of the endogenous variables to converge to their co-integrating relationships while allowing for short-run adjustment dynamics. The cointegration term is known as the error correction term since the deviation from long-run equilibrium is corrected gradually through a series of partial short-run adjustments.

To take the simplest possible example, consider a two variable system with one cointegrating equation and no lagged difference terms. The co-integrating equation is:

$$
y_{2, t}=\beta y_{1, t} \quad(1)
$$

The corresponding VEC model is:

$$
\begin{aligned}
& \Delta y_{1, t}=\alpha_{1}\left(y_{2, t-1}-\beta y_{1, t-1}\right)+\varepsilon_{1, t} \\
& \Delta y_{2, t}=\alpha_{2}\left(y_{2, t-1}-\beta y_{1, t-1}\right)+\varepsilon_{2, t}
\end{aligned}
$$

In this simple model, the only right-hand side variable is the error correction term. In long run equilibrium, this term is zero. However, if $y_{1}$ and $y_{2}$ deviate from the long run equilibrium, the error correction term will be nonzero and each variable adjusts to partially restore the equilibrium relation. The coefficient $\alpha_{i}$ measures the speed of adjustment of the $i$ i-th endogenous variable towards the equilibrium.

The vector of the endogenous variables has the following representation:

$$
\left.Y_{t}=\text { bet }_{t} \text { rpd }{ }_{t} \text { bubid }{ }_{t} \text { ri }{ }_{t} \text { roneuro }{ }_{t} \text { ronusd }{ }_{t}\right\rfloor(3)
$$

Where:

bet is the composite index of the Stock Exchange of Bucharest,

rpd is the average level of the ,passive" interest rate (the interest rate including the bonus offered by the commercial banks for the deposits of non banking clients),

bubid is the interest rate for the deposits collected from the inter-banking market,

$r i$ is the inflation rate calculated on the basis of monthly variations of the Consumption Price Ratio,

roneuro is the exchange rate of the ROL in respect to the EURO, ronusd is the exchange rate of the ROL in respect to the USD.

One can notice the fact that the model takes into account endogenous variables. This way, we can presume the absence of a representative ratio for the financial markets from the MEU. In case of exogenous variable, the presumption can be regarded as „questionable”. Nevertheless, preliminary tests suggest the existence of a ,week integration" state of the Romanian financial market into the international financial flows. Therefore, we preferred not to take it into account. We can also see that the variables taken into account in the explanatory set are mainly nominal variables, less able to reflect the structural characteristics of the Romanian economy (exception being the inflation).

\section{Results.}

For an analysis period starting in January 2000 and ending in December 2006, the stationary (who's results are presented bellow) (Augmented Dickey-Fuller, Phillips-Perron, KwiatkowskiPhillips-Schmidt-Shin, and Elliott-Rothenberg-Stock) suggest the fact that all the involved 
variables can be regarded as $I(1)$ type variables (the data are gathered from the monthly bulletins of the National Bank of Romania).

Also, the JOHANSEN co-integration test suggests the existence of three co-integration relations between these variables (more exactly, the Trace test suggests eight co-integration relations, while the Maximum Eigenvalue indicates three relations; we shall consider three cointegration relations that try to "lock" the variables that are specific to the financial market and to integrate them into an individualized block in respect to the other variables).

Table 1

The JOHANSEN co-integration test for the variables of the number (3) equation

Number of included observations: 118

Linear deterministic trend

Trace Test

Number of co-integration relations Statistics

Critical values

for a 0.05 limit

Eigenvalue Trace

Prob.**

\begin{tabular}{lllll}
\hline \hline None $*$ & 0.634957 & 236.9415 & 143.6691 & 0.0000 \\
One at the most $*$ & 0.477148 & 163.3766 & 111.7805 & 0.0000 \\
Two at the most $*$ & 0.423954 & 116.0392 & 83.93712 & 0.0000 \\
Three at the most $*$ & 0.337384 & 75.77485 & 60.06141 & 0.0014 \\
Four at the most $*$ & 0.197264 & 45.73095 & 40.17493 & 0.0125 \\
Five at the most $*$ & 0.178734 & 29.69068 & 24.27596 & 0.0094 \\
Six at the most $*$ & 0.105385 & 15.31635 & 12.32090 & 0.0153 \\
Seven at the most $*$ & 0.093760 & 7.186949 & 4.129906 & 0.0087
\end{tabular}

The Trace test indicates the existence of eight co-integration relations for a critical limit of 0.05

* means the rejection of the hypothesis for a critical limit of 0.05

** $\mathrm{p}$ values given by MacKinnon-Haug-Michelis (1999)

The Maximum Eigenvalue Test

Number of co-integration

relations
Statistics

Eigenvalue Trace
Critical values for a

0.05 limit

Prob.**

$\begin{array}{lllll}\text { None } * & 0.634957 & 73.56494 & 48.87720 & 0.0000 \\ \text { One at the most } * & 0.477148 & 47.33734 & 42.77219 & 0.0146 \\ \text { Two at the most } * & 0.423954 & 40.26439 & 36.63019 & 0.0180 \\ \text { Three at the most } & 0.337384 & 30.04390 & 30.43961 & 0.0559 \\ \text { Four at the most } & 0.197264 & 16.04027 & 24.15921 & 0.4182 \\ \text { Five at the most } & 0.178734 & 14.37433 & 17.79730 & 0.1522 \\ \text { Six at the most } & 0.105385 & 8.129406 & 11.22480 & 0.1663 \\ \text { Seven at the most } * & 0.093760 & 7.186949 & 4.129906 & 0.0087\end{array}$

The Maximum Eigenvalue test indicates the existence of three co-integration relations for a critical limit of 0.05

* means the rejection of the hypothesis for a critical limit of 0.05 ,

** $\mathrm{p}$ values given by MacKinnon-Haug-Michelis (1999) 
The quality of the estimation can be considered as "satisfactory", fact confirmed by the test regarding the unitary roots of the characteristic polynom.

\section{Table 2}

\section{The stability of the SVAR model}

\begin{tabular}{cc}
\hline \hline Root & Modulus \\
\hline \hline 1.000000 & 1.000000 \\
1.000000 & 1.000000 \\
1.000000 & 1.000000 \\
1.000000 & 1.000000 \\
1.000000 & 1.000000 \\
$-0.208573+0.839023 \mathrm{i}$ & 0.864559 \\
$-0.208573-0.839023 \mathrm{i}$ & 0.864559 \\
0.831235 & 0.831235 \\
$-0.565862+0.608823 \mathrm{i}$ & 0.831184 \\
$-0.565862-0.608823 \mathrm{i}$ & 0.831184 \\
-0.788669 & 0.788669 \\
$0.119503-0.760917 \mathrm{i}$ & 0.770244 \\
$0.119503+0.760917 \mathrm{i}$ & 0.770244 \\
$-0.717446+0.252650 \mathrm{i}$ & 0.760632 \\
$-0.717446-0.252650 \mathrm{i}$ & 0.760632 \\
$-0.038977-0.741893 \mathrm{i}$ & 0.742916 \\
$-0.038977+0.741893 \mathrm{i}$ & 0.742916 \\
$0.548140+0.471472 \mathrm{i}$ & 0.723010 \\
$0.548140-0.471472 \mathrm{i}$ & 0.723010 \\
$-0.375759+0.592318 \mathrm{i}$ & 0.701453 \\
$-0.375759-0.592318 \mathrm{i}$ & 0.701453 \\
$0.214480-0.636140 \mathrm{i}$ & 0.671324 \\
$0.214480+0.636140 \mathrm{i}$ & 0.671324 \\
$-0.369641-0.507365 \mathrm{i}$ & 0.627737 \\
$-0.369641+0.507365 \mathrm{i}$ & 0.627737 \\
$-0.478554-0.192796 \mathrm{i}$ & 0.515931 \\
$-0.478554+0.192796 \mathrm{i}$ & 0.515931 \\
$0.337862+0.356450 \mathrm{i}$ & 0.491129 \\
$0.337862-0.356450 \mathrm{i}$ & 0.491129 \\
$0.032067+0.425461 \mathrm{i}$ & 0.426668 \\
$0.032067-0.425461 \mathrm{i}$ & 0.426668 \\
0.391480 & 0.391480 \\
\hline \hline & \\
\hline & \\
\hline
\end{tabular}

VEC specification imposes 5 unit $\operatorname{root}(\mathrm{s})$. VAR satisfy the stability conditions.

By analyzing the form of these functions, one can notice that the shocks upon the considered variables have relative quick effects upon the dynamics of the financial market ratio. The ,peak of repercussion" is reached in about 3-6 months, and in the 11-12 months to follow it slowly "dies". Moreover, if we compare the magnitude of the individual variables exercised impact, the results suggest the fact that the most important influence factors are represented by the interest rate from the monetary market. Per a contrario, the passive interest rate and the inflation rate have little impact. The RON/USD exchange rate has a much more significant impact over the in comparison 
with the RON/EURO exchange rate. One possible explanation is the structure of the financial resources of the investments funds.

\section{Conclusions.}

The results obtained show the different impact that the explanatory variables took in account have upon the dynamics of the composite index of the Stock Exchange of Bucharest.

While in the analyzed period of time the real exchange rate associated to the investments in lei was normally under or just a little bit over the inflation rate, the traditional preference for keeping foreign currencies instead of investments in lei was more evident in the firs decade of the analyzed period (until 2002) and was maintained also in the last analyzed period (2004-2006). Taking into account the fact that in the last few years were implemented politics of controlled floating of the national currency that have lead to a relative stability of the national currency, the normal reaction of the investors should have been the change of preference towards other forms of saving. Still, this process was not as ample as it was wanted because of the psychological compound of the investing behavior.

If these factors of investor sentiment had a direct impact on developed markets, what happened on emerging markets, and especially in CEECs, was largely determined by marking profits and portfolio readjustments by international investors. There are several reasons supporting the idea of a non-discriminative capital flight from the emerging markets: (1) there were no economic fundamentals to trigger such corrections, (2) the stock prices of listed companies had the tendency of falling altogether irrespective of the companies' profile or performance.

\section{Bibliography:}

1. Amisano, Giannini,C. Topics in Structural VAR Econometrics, 2nd Edition, February 1997, Springer, New York

2. Cobbaut R., „Théorie Financière”, $3^{\mathrm{e}}$ édition, Ed. Economica, Paris, 1994

3. Annual Reports, National Bank of Romania, 2000-2006 